\title{
Hydroxyapatite-forming capability and mechanical properties of organic-inorganic hybrids and $\alpha$-tricalcium phosphate porous bodies
}

\author{
Tomohiro UCHINO, ${ }^{\dagger}$ Masanobu KAMITAKAHARA, ${ }^{*}$ Makoto OTSUKA and Chikara OHTSUKI ${ }^{* *}$ \\ Research Institute of Pharmaceutical Science, Musashino University, 1-1-20, Shinmachi, Nishitokyo-shi, Tokyo, $202-8585$ \\ ${ }^{*}$ Graduate School of Environmental Studies, Tohoku University, 6-6-20, Aoba, Aramaki, Aoba-ku, Sendai 980-8579 \\ ${ }^{* *}$ Graduate school of Engineering, Nagoya University, Furo-cho, Chikusa-ku, Nagoya, 464-8603
}

\begin{abstract}
We have fabricated $\alpha$-TCP porous body (pTCP)/hybrid polymer composites consisting of 2-hydroxyethylmethacrylate (HEMA) and 3-methacryloxypropyltrimethoxysilane (MPS) (pTCP/H). The composites showed an apatite-forming capability in a simulated body fluid (SBF) and a higher compressive strength (57 MPa) than pTCP (0.60 MPa). The compressive strength was still lower than human cortical bone (100-230 MPa). Moreover, there was a problem in that some samples formed cracks after soaking in the SBF due to the swelling of the HEMA-MPS polymer. Compared with HEMA, methylmethacrylate (MMA) does not show any swelling after polymerization, and is expected to have a higher mechanical strength than HEMA. We also fabricated a composite from pTCP and a hybrid polymer consisting of MMA and MPS (pTCP/M). The compressive strength of pTCP/M (94 MPa) was higher than that of pTCP/H before soaking in the SBF. The pTCP/M formed a hydroxyapatite layer in the SBF. The pTCP/M did not form cracks, even after soaking in the SBF. The pTCP/M showed both bioactivity and a high compressive strength. This type of composite has potential for novel bone substitute.
\end{abstract}

(02010 The Ceramic Society of Japan. All rights reserved.

Key-words : Bioresorbable ceramics, Tricalcium phosphate, Hydroxyapatite, Simulated body fluid, Composite, Mechanical properties

[Received August 31, 2009; Accepted November 19, 2009]

\section{Introduction}

In general, artificial materials implanted into bone defects are encapsulated by fibrous tissue and are isolated from the surrounding bones. However, some ceramics can form direct bonds to living bone. These so-called bioactive ceramics, such as Bioglass $^{\circledR},{ }^{1)}$ glass-ceramic $\mathrm{A}-\mathrm{W},{ }^{2)}$ and sintered hydroxyapatite ${ }^{3)}$ are attractive as bone substitutes because they bond spontaneously to living bone after implantation in bony defects. ${ }^{4)}$ However, their applications are still limited because of their brittleness. An essential requirement for artificial materials to show bonebonding capability, i.e., bioactivity, is to form a bone-like hydroxyapatite (HAp) layer on their surfaces in the body environment. $^{5), 6)}$ The potential to form a bone-like HAp layer is evaluated by in vitro examination using a simulated body fluid (SBF), as proposed by Kokubo et al. ${ }^{7-9)}$ An SBF is an extracellular solution that has ion concentrations similar to those of human blood plasma. Previous studies on the formation of bonelike HAp layers in an SBF have already revealed that silanol groups $(\mathrm{Si}-\mathrm{OH})$ on the material's surface provide effective sites for heterogeneous nucleation of HAp in the body environment, ${ }^{10}$ ) and the release of calcium ions $\left(\mathrm{Ca}^{2+}\right)$ from the materials enhances HAp formation by increasing the degree of supersaturation with respect to HAp in surrounding fluids. ${ }^{11)}$

It is expected that if calcium ions are incorporated into an organically modified silicate structure, then the hybrid obtained could show both HAp-forming capability on its surface in a body

Corresponding author: T. Uchino; E-mail: t_uchino@musashinou.ac.jp environment and flexibility. Tsuru et al. ${ }^{12)}$ reported that some polydimethylsiloxane (PDMS) $-\mathrm{CaO}-\mathrm{SiO}_{2}$ hybrids prepared by a sol-gel method formed apatite in an SBF. This indicates that these hybrids can be bioactive. Since this report, many researchers have reported such bioactive hybrids. ${ }^{13)-16)}$ Recently, we reported on the synthesis of an organic-inorganic hybrid starting from 2hydroxyethylmethacrylate (HEMA) and 3-methacryloxypropyltrimethoxysilane (MPS), in combination with calcium chloride $\left(\mathrm{CaCl}_{2}\right){ }^{17)-19)}$ Such an organic-inorganic hybrid has the potential to show both bioactivity and flexibility. However, hybrids that contain calcium ions can show a significant decrease in their mechanical strength in the body environment when the calcium ions are added as highly water-soluble calcium salts. ${ }^{20)}$ Therefore, we focused on calcium phosphates with adequate solubility as a source of calcium ions, because these can also provide reinforcement to the hybrid. In a previous study, we fabricated composites of HEMA-MPS hybrids and calcium phosphates. ${ }^{21)}$ However, the mechanical strength of a composite of an HEMAMPS hybrid and an $\alpha$-tricalcium phosphate $(\alpha$-TCP) porous body ${ }^{22,23)}$ was significantly decreased, and some samples formed cracks after soaking them in an SBF because of the swelling of the HEMA-MPS. Self-setting calcium phosphate powder $(\mathrm{CPP})^{24), 25)}$ did not provide enough reinforcement of the HEMAMPS hybrid.

We thought that methylmethacrylate (MMA) would not show such swelling after polymerization compared with HEMA, and it is expected to provide a higher mechanical strength than HEMA. This composite should also be applicable for dental materials. In this study, we fabricated a composite of an $\alpha$-TCP porous body and a hybrid polymer consisting of MMA and MPS. 
The mechanical properties of the $\alpha$-TCP porous body (pTCP), a composite of the $\alpha$-TCP porous body and an HEMA-MPS hybrid (pTCP/H), and a composite of an $\alpha$-TCP porous body and an MMA-MPS hybrid (pTCP/M) were evaluated both before and after soaking in an SBF. The formation of HAp on the samples was examined after soaking in the SBF.

\section{Materials and methods}

\subsection{Preparation of $\alpha$-TCP porous body}

The $\alpha$-TCP porous bodies (pTCP) were fabricated using the method reported by Kitamura et al. ${ }^{22), 23)}$ Commercial $\beta$-TCP powder (Nacalai Tesque, Inc.), potato starch (Nacalai Tesque, Inc.), and ultra-pure water were mixed in a mass ratio of 8:8:7. The resulting slurry was impregnated in a $15 \times 15 \times 15 \mathrm{~mm}^{3}$ polyurethane sponge containing pores with a diameter of $1000 \mu \mathrm{m}$. The sample was dried at $60^{\circ} \mathrm{C}$ for a period of $1 \mathrm{~h}$, followed by heating at $1000^{\circ} \mathrm{C}$ for a period of $3 \mathrm{~h}$ in air to burn off the sponge. After cooling to room temperature, the sample was heated at $1400^{\circ} \mathrm{C}$ for a period of $12 \mathrm{~h}$, followed by cooling to room temperature at the natural cooling rate of the furnace.

\subsection{Preparation of $\alpha$-TCP porous body and organic-inorganic hybrid composite}

A scheme showing the preparation of pTCP and the pTCP and organic-inorganic hybrid composite is shown in Fig. 1. Two types of composites were prepared from pTCP, and two types of hybrid were fabricated. One composite was prepared from pTCP and a hybrid consisting of HEMA $\left(\mathrm{CH}_{2}=\mathrm{C}\left(\mathrm{CH}_{3}\right) \mathrm{COO}\left(\mathrm{CH}_{2}\right)_{2} \mathrm{OH}\right.$, Wako Pure Chemical Industries, Ltd.) and MPS $\left(\mathrm{CH}_{2}=\right.$ $\mathrm{C}\left(\mathrm{CH}_{3}\right) \mathrm{COO}\left(\mathrm{CH}_{2}\right)_{3} \mathrm{Si}\left(\mathrm{OCH}_{3}\right)_{3}$, Chisso Corporation), while the other composite was prepared from pTCP and a hybrid consisting of methylmethacrylate (MMA: $\mathrm{CH}_{2}=\mathrm{C}\left(\mathrm{CH}_{3}\right) \mathrm{COOCH}_{3}$, Wako Pure Chemical Industries, Ltd.) and MPS. Reagent-grade HEMA, MPS, and MMA were used as the starting reagents without further purification. Mixtures of the HEMA and MPS monomers or MMA and MPS monomers in molar ratios of 9:1 with $1 \mathrm{~mol} \%$ benzoyl peroxide (BPO) were impregnated with pTCP under vacuum. Then, the pTCP and the monomer solution were heated to $60^{\circ} \mathrm{C}$ for a period of $2 \mathrm{~h}$, followed by drying under ambient conditions. The composite obtained was denoted as pTCP/H. The composite consisting of pTCP and a hybrid made from MMA and MPS was prepared using the same method as $\mathrm{pTCP} / \mathrm{H}$, and was denoted as $\mathrm{pTCP} / \mathrm{M}$.

\subsection{Calculation of the porosity}

The density of the HEMA-MPS and MMA-MPS hybrids was calculated from the weight and volume, assuming that the hybrids did not contain pores. The porosity of pTCP was also calculated from its weight and volume. The density of $\alpha$-TCP is $2.86 \mathrm{~g} \cdot \mathrm{cm}^{-3} \cdot{ }^{26)}$ The porosity of $\mathrm{pTCP} / \mathrm{H}$ and $\mathrm{pTCP} / \mathrm{M}$ was calculated from their weight and volume using the density of the HEMA-MPS hybrid, the MMA-MPS hybrid, and the porosity of pTCP.

\subsection{Examination of the mechanical properties}

The mechanical properties of the pTCP, pTCP/H, and pTCP/ $\mathrm{M}$ samples were evaluated from a compressive test using a universal testing machine (Model 5566, Instron, Co., USA). The maximum load was defined as the compressive strength when a $5 \times 5 \times 10 \mathrm{~mm}^{3}$ rectangular sample was loaded using a constant crosshead speed of $20 \mathrm{~mm} / \mathrm{min}$.

\subsection{Examination of bioactivity}

To estimate the bioactivity of the samples, the HAp-forming capability of the composites was evaluated by soaking them in an SBF (ion concentrations: $\mathrm{Na}^{+}=142.0, \mathrm{~K}^{+}=5.0, \mathrm{Mg}^{2+}=1.5$, $\mathrm{Ca}^{2+}=2.5, \mathrm{Cl}^{-}=147.8, \mathrm{HCO}_{3}{ }^{-}=4.2, \mathrm{HPO}_{4}{ }^{2-}=1.0$, and $\mathrm{SO}_{4}{ }^{2-}=$ $0.5 \mathrm{mmol} \cdot \mathrm{dm}^{-3}$ ) at $\mathrm{pH}=7.25$ at $36.5^{\circ} \mathrm{C}^{7)-9)} \mathrm{A} 10 \times 10 \times 1 \mathrm{~mm}^{3}$
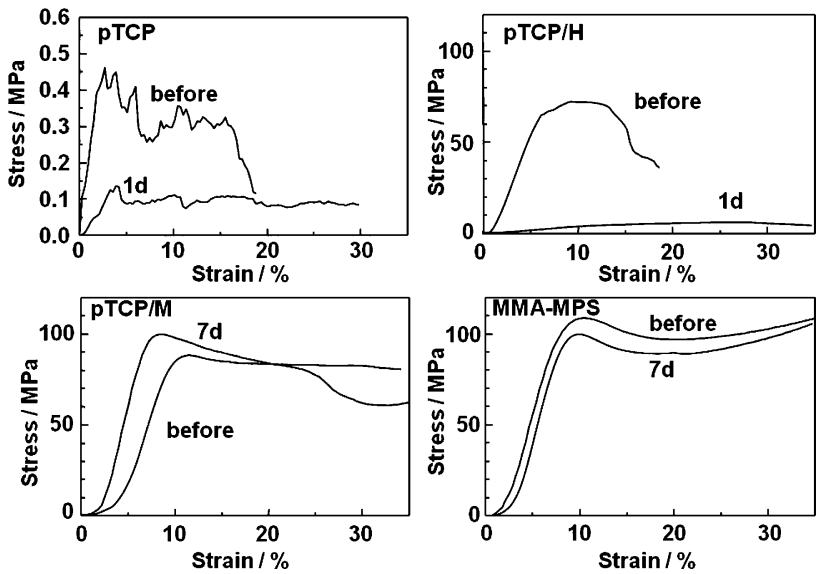

Fig. 2. Stress-strain curves of pTCP, pTCP/H, pTCP/M and MMAMPS before and after soaking in SBF for various periods.

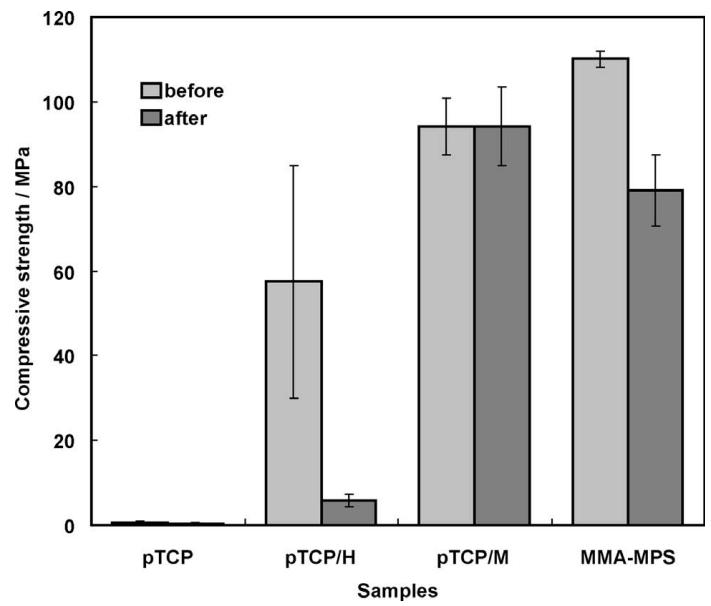

Fig. 3. Compressive strength of pTCP, pTCP/H, pTCP/M and MMAMPS before and after soaking in SBF for $7 \mathrm{~d}$. 
rectangular sample was cut by micro cutting machine (BS300CP, Meiwafosis Co., Ltd.) from the bulk samples and soaked in $35 \mathrm{~cm}^{3}$ of SBF. This was kept at $36.5^{\circ} \mathrm{C}$ for periods of 3 and $7 \mathrm{~d}$, and the surfaces of the samples before and after soaking in the SBF were characterized using thin-film X-ray diffraction (TF-XRD, RINT2200V/PC-LR, Rigaku Co.), and scanning electron microscopy (SEM, S-4800, Hitachi, Ltd.). Changes in calcium $(\mathrm{Ca})$ and phosphorus $(\mathrm{P})$ concentrations of SBF before and after immersion of the specimens were measured by inductively coupled plasma atomic emission spectroscopy (ICP-AES: optima2000, PerkinElmer, Germany).

\section{Results}

The density of the HEMA-MPS and MMA-MPS hybrids was 1.21 and $1.16 \mathrm{~g} \cdot \mathrm{cm}^{-3}$. The porosity of pTCP was $80 \%$. From these densities and the porosity, the porosity of $\mathrm{pTCP} / \mathrm{H}$ and pTCP/M was calculated $30 \%$ and $12 \%$. Figures 2, 3, and $\mathbf{4}$ and Table 1 show the stress-strain curves, the compressive strength,

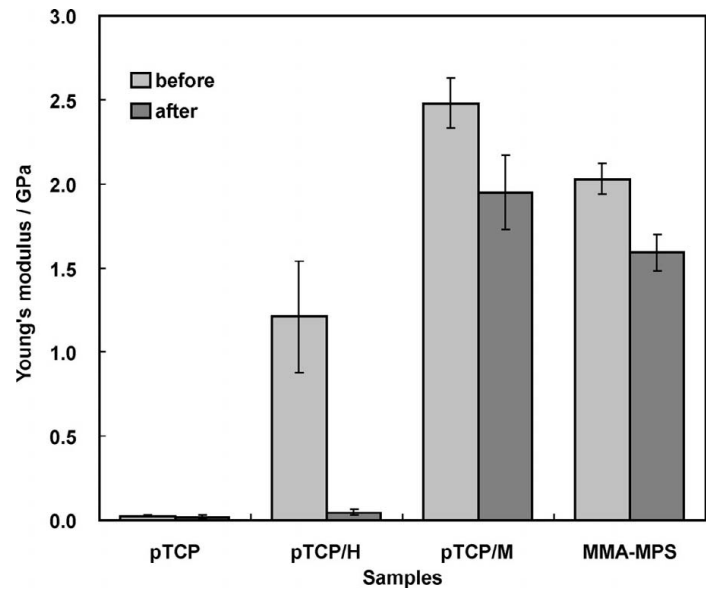

Fig. 4. Young's modulus of $\mathrm{pTCP}, \mathrm{pTCP} / \mathrm{H}, \mathrm{pTCP} / \mathrm{M}$ and MMA-MPS before and after soaking in SBF for $7 \mathrm{~d}$. and the Young's modulus of the samples before and after soaking in the SBF, compared with the properties of human bone. ${ }^{27)}$ The compressive strength before soaking in the SBF increased in the sequence: pTCP $<$ pTCP/H $<$ pTCP/M $<$ MMA-MPS. The Young's modulus before soaking in SBF increased in the sequence: pTCP $<$ pTCP/H $<$ MMA-MPS $<$ pTCP/M. The compressive strength and Young's modulus were improved by incorporating the hybrids, and the contribution to the improvement by MMA-MPS was larger than that of HEMA-MPS. The porosity of these samples contributed to these compressive strengths. The compressive strength of $\mathrm{pTCP} / \mathrm{M}$ was similar to that of cortical bone, although the Young's modulus of $\mathrm{pTCP} / \mathrm{M}$ was lower than that of cortical bone. After soaking in the SBF for a period of $3 \mathrm{~d}$, the compressive strength and the Young's modulus of $\mathrm{pTCP} / \mathrm{H}$ decreased significantly, and some of the $\mathrm{pTCP} / \mathrm{H}$ samples could not undergo any mechanical tests as they formed cracks. In contrast, pTCP/M did not form cracks, and did not show a significant decrease in its compressive strength and Young's modulus after soaking in the SBF for a period of $3 \mathrm{~d}$.

Table 1. Mechanical Properties of pTCP, pTCP/H, pTCP/M, MMAMPS and Human Bone Before and After Soaking in SBF

\begin{tabular}{lcc}
\hline \multicolumn{1}{c}{ Samples } & $\begin{array}{c}\text { Compressive } \\
\text { strength/MPa }\end{array}$ & $\begin{array}{c}\text { Young's modulus } \\
/ \mathrm{GPa}\end{array}$ \\
\hline pTCP befroe $(\mathrm{n}=5)$ & $0.59 \pm 0.16$ & $0.025 \pm 0.003$ \\
pTCP after 1 d $(\mathrm{n}=5)$ & $0.40 \pm 0.26$ & $0.015 \pm 0.011$ \\
pTCP/H before $(\mathrm{n}=5)$ & $57.4 \pm 27.5$ & $1.21 \pm 0.33$ \\
pTCP/H after 1 d $(\mathrm{n}=5)$ & $5.8 \pm 1.5$ & $0.047 \pm 0.02$ \\
pTCP/M before $(\mathrm{n}=3)$ & $94.2 \pm 6.6$ & $2.48 \pm 0.15$ \\
pTCP/M after 7 d $(\mathrm{n}=3)$ & $94.1 \pm 9.4$ & $1.95 \pm 0.22$ \\
MMA-MPS before $(\mathrm{n}=3)$ & $110 \pm 2$ & $2.03 \pm 0.09$ \\
MMA-MPS after 7 d $(\mathrm{n}=3)$ & $79.1 \pm 8.4$ & $1.59 \pm 0.11$ \\
Cortical bone & $100-230$ & $7.00-30.0$ \\
Cancellous bone & $2-12$ & $0.5-0.05$ \\
\hline
\end{tabular}

PTCP

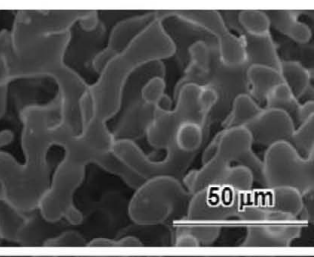

$3 d$

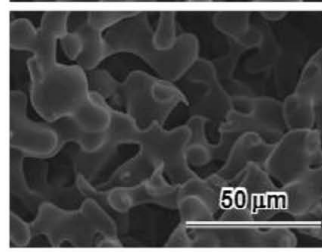

od

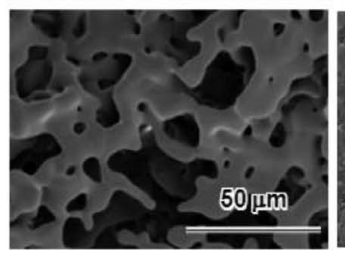

PTCP/H

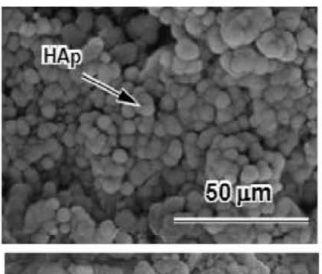

pTCP/M
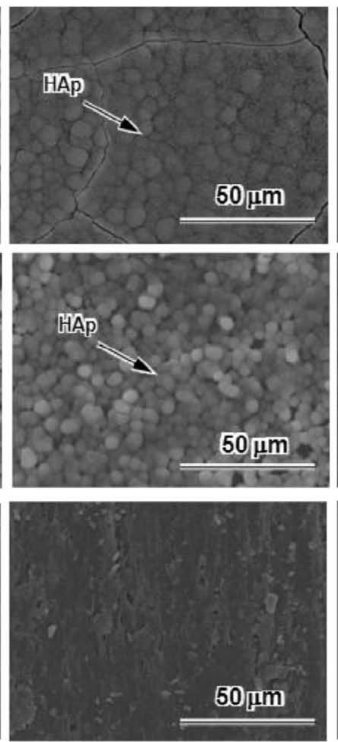

MMA-MPS

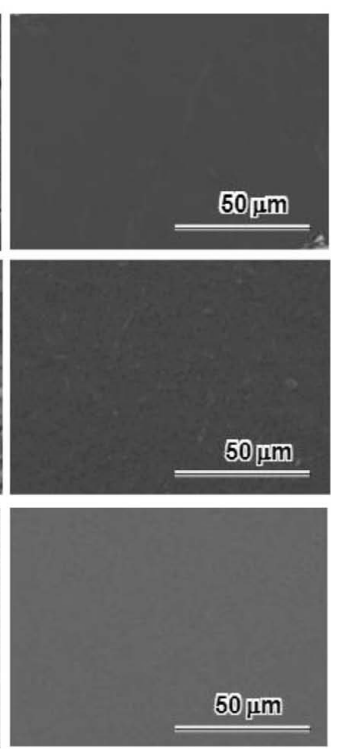

Fig. 5. SEM images of pTCP, pTCP/H, pTCP/M and MMA-MPS before and after soaking in SBF for 3 and $7 \mathrm{~d}$. 

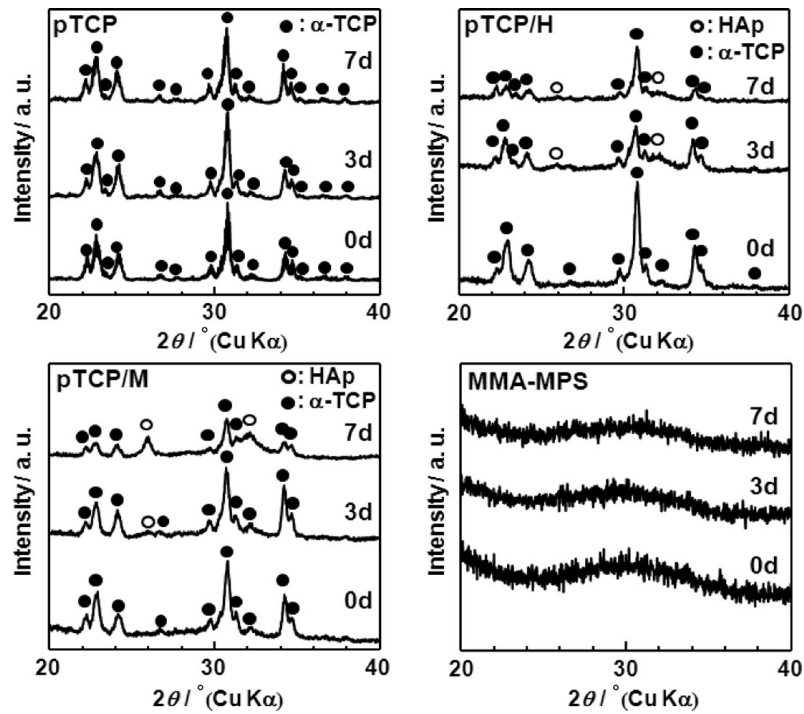

Fig. 6. TF-XRD patterns of pTCP, pTCP/H, pTCP/M and MMAMPS before and after soaking in SBF for $7 \mathrm{~d}$.
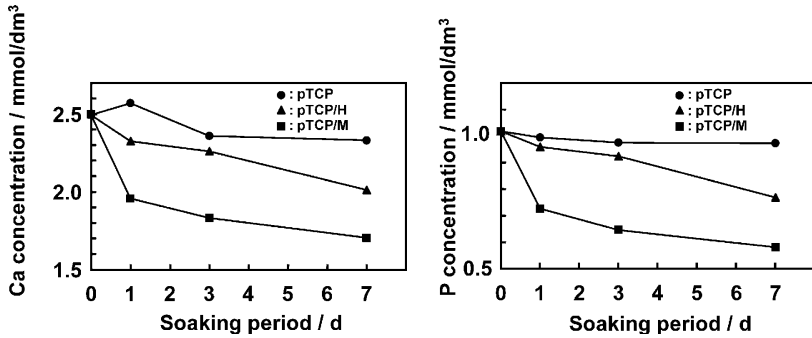

Fig. 7. $\mathrm{Ca}$ and $\mathrm{P}$ concentrations of $\mathrm{pTCP}, \mathrm{pTCP} / \mathrm{H}$ and $\mathrm{pTCP} / \mathrm{M}$ before and after soaking in SBF for $7 \mathrm{~d}$.

Figure 5 shows SEM images of pTCP, pTCP/H, and pTCP/M before and after soaking in the SBF for a period of $7 \mathrm{~d}$. The pores were partially filled when the polymer was loaded before soaking in the SBF. The porosity of the samples increased in the sequence: $\mathrm{pTCP} / \mathrm{M}<\mathrm{pTCP} / \mathrm{H}<\mathrm{pTCP}$. After soaking in the SBF for a period of $3 \mathrm{~d}$, spherical particles were formed on the surface of the $\mathrm{pTCP} / \mathrm{H}$ and $\mathrm{pTCP} / \mathrm{M}$. Then, after soaking in SBF for $7 \mathrm{~d}$, the surfaces of these samples were covered with spherical particles. Figure 6 shows that these particles were assigned to HAp from the TF-XRD patterns. Changes in $\mathrm{Ca}$ and $\mathrm{P}$ concentrations of SBF before and after immersion of the specimens were shown in Fig. 7. Remarkable decreases in $\mathrm{Ca}$ and $\mathrm{P}$ were observed on pTCP/H and pTCP/M. The decrease of $\mathrm{Ca}$ and $\mathrm{P}$ concentration of pTCP/H after soaking in SBF was larger than that of pTCP/M. In contrast, $\mathrm{Ca}$ and $\mathrm{P}$ concentrations were nearly constant during soaking of pTCP.

\section{Discussion}

In the case of the pTCP/H sample, the HEMA-MPS swelled due to the incorporation of water, and this induced many cracks in the sample. The resultant cracks decreased the compressive strength and Young's modulus. ${ }^{21)}$ In contrast, MMA-MPS did not swell much, since MMA is more hydrophobic than HEMA. This hydrophobic property induced the lower decrease of $\mathrm{Ca}$ and $P$ concentration after soaking in SBF. Using the MMA-MPS system, we obtained a composite that had both an apatite-forming capability and kept its mechanical properties after soaking in an
SBF for a period of $7 \mathrm{~d}$.

It is clear that the potential for HAp formation by the MMAMPS hybrid without the presence of calcium ions is low in an SBF. Moreover, an $\alpha$-TCP porous body on its own does not form HAp in an SBF within a period of $7 \mathrm{~d}$. In contrast, HAp formation in an SBF was induced by combining an $\alpha$-TCP porous body with the organic-inorganic hybrids synthesized from HEMA and MPS and from MMA and MPS. A surface treatment of $\alpha$-TCP ceramics by polishing using an abrasive paper has a higher potential for inducing hydroxyapatite nucleation on the surface of TCP ceramics in an $\mathrm{SBF}^{28), 29)}$ This suggests that the release of calcium and phosphate ions from the $\alpha$-TCP porous body does not allow for heterogeneous nucleation on the surface of these hybrids, while the existence of silanol $(\mathrm{Si}-\mathrm{OH})$ groups formed on the surface of the HEMA-MPS and MMA-MPS hybrids from the hydrolysis of the MPS may also be insufficient to allow for heterogeneous nucleation of HAp on the surface of these hybrids. The coexistence of a plane surface from the bulk material and the release of calcium and phosphate ions are important for inducing the heterogeneous nucleation of HAp in a body environment. Such cooperative effect from both materials is interesting for the design of novel bioactive composites that show bone-bonding properties.

The incorporation of an $\alpha$-TCP porous body with HEMAMPS or MMA-MPS hybrids resulted in the reinforcement of the mechanical strength and Young's modulus before soaking in an SBF. The continuous ceramic framework of the $\alpha$-TCP porous body was effective in increasing the mechanical strength and the Young's modulus. However, the compressive strength and the Young's modulus of $\mathrm{pTCP} / \mathrm{H}$ decreased after soaking in the SBF for a period of $1 \mathrm{~d}$. The decrease in compressive strength of the composite $\mathrm{pTCP} / \mathrm{H}$ was caused by the decrease in mechanical strength of both the HEMA-MPS hybrid and the pTCP. The MMA-MPS in the pTCP/M prevented a significant decrease in the mechanical properties due to the small change in volume.

\section{Conclusion}

HEMA-MPS and MMA-MPS hybrids reinforced $\alpha$-TCP porous bodies. After soaking in an SBF, the mechanical properties of a composite made of MMA-MPS and an $\alpha$-TCP porous body were similar to those before soaking, while a significant decrease in the mechanical properties of a composite made of HEMA-MPS and an $\alpha$-TCP porous body was observed. The resulting composites formed HAp on their surfaces in an SBF within a period of $3 \mathrm{~d}$. The cooperative effect of the organicinorganic hybrid with an $\alpha$-TCP porous body provides the potential to increase the mechanical properties and the bioactivity, making such materials suitable for bone-repairing applications.

\section{References}

1) L. L. Hench, R. J. Splinter, W. C. Allen and T. K. Greenlee, J. Biomed. Mater. Res. Symp., 2, 117-141 (1971).

2) T. Kokubo, M. Shigematsu, Y. Nagashima, M. Tashiro, T. Nakamura, T. Yamamuro and S. Higashi, Bull. Inst. Chem. Res. Kyoto Univ., 60, 260-268(1982).

3) M. Jarcho, J. F. Kay, K. I. Gumaer, R. H. Doremus and H. P. Drobeck, J. Bioeng., 1, 79-92 (1977).

4) L. L. Hench, J. Am. Ceram. Soc., 81, 1705-1728 (1998).

5) T. Kokubo, J. Ceram. Soc. Japan, 99, 965-973 (1991).

6) H.-M. Kim, J. Ceram. Soc. Japan, 109, S49-S57 (2001).

7) T. Kokubo, H. Kushitani, S. Sakka, T. Kitsugi and T. Yamamuro, J. Biomed. Mater. Res., 24, 721-734 (1990).

8) S.-B. Cho, K. Nakanishi, T. Kokubo, N. Soga, C. Ohtsuki, T. 
Nakamura, T. Kitsugi and T. Yamamuro, J. Am. Ceram. Soc., 78, 1769-1774 (1995).

9) T. Kokubo and H. Takadama, Biomaterials, 27, 2907-2915 (2006).

10) P. Li, C. Ohtsuki, T. Kokubo, K. Nakanishi, N. Soga, T. Nakamura and T. Yamamuro, J. Am. Ceram. Soc., 75, 20942097 (1992).

11) C. Ohtsuki, T. Kokubo and T. Yamamuro, J. Non-Cryst. Solids, 143, 84-92 (1992).

12) K. Tsuru, C. Ohtsuki, A. Osaka, T. Iwamoto and J. D. Mackenzie, J. Mater. Sci., Mater. Med., 8, 157-161 (1997).

13) Q. Chen, F. Miyaji, T. Kokubo and T. Nakamura, Biomaterials, 20, 1127-1132 (1999).

14) M. Kamitakahara, M. Kawashita, N. Miyata, T. Kokubo and T. Nakamura, J. Sol-Gel Sci. Tech., 21, 75-81 (2001).

15) M. Kamitakahara, M. Kawashita, N. Miyata, T. Kokubo and T. Nakamura, J. Mater. Sci.: Mater. Med., 13, 1015-1020 (2002).

16) S.-H. Rhee, J. Y. Choi and H.-M. Kim, Biomaterials, 23, 4915-4921 (2002).

17) C. Ohtsuki, T. Miyazaki and M. Tanihara, Mater. Sci. Engi. C, 22, 27-34 (2002).

18) T. Miyazaki, C. Ohtsuki and M. Tanihara, J. Nanosci. Nanotechnol., 3, 511-515 (2003).
19) C. Ohtsuki, M. Kamitakahara and T. Miyazaki, Ann. Chim. Sci. Mat., 29, 29-39 (2004).

20) M. Kamitakahara, M. Kawashita, N. Miyata, T. Kokubo and T. Nakamura, J. Am. Ceram. Soc., 87, 235-239 (2004).

21) T. Uchino, C. Ohtsuki, M. Kamitakahara, M. Tanihara and T. Miyazaki, J. Ceram. Soc. Japan, 114, 692-696 (2006).

22) M. Kitamura, C. Ohtsuki, H. Iwasaki, S. Ogata, M. Tanihara and T. Miyazaki, J. Mater. Sci.: Mater. Med., 15, 1153-1158 (2004).

23) M. Kitamura, C. Ohtsuki, S. Ogata, M. Kamitakahara and M. Tanihara, Mater. Trans., 45, 983-988 (2004).

24) P. Brown and L. C. Chow, "Cement research progress," American Ceramic Society, Westfield (1986) pp. 351-379.

25) K. Ishikawa, S. Takagi, L. C. Chow and K. Suzuki, J. Biomed. Mater. Res., 46, 504-510 (1999).

26) M. Mathew, L. W. Schroeder, B. Dickens and W. E. Brown, Acta. Crystallogr., B33, 1325-1333 (1977).

27) L. L Hench and J. Wilson, "An introduction to bioceramics," World Scientific, Singapore (1993) pp. 1-24.

28) T. Uchino, K. Yamaguchi, G. Kawachi, K. Kikuta, M. Kamitakahara and C. Ohtsuki, J. Ceram. Soc. Japan, 115 (2008).

29) T. Uchino, C. Ohtsuki, M. Kamitakahara, M. Tanihara and T. Miyazaki, Key Eng. Mater., 309-311, 251-254 (2006). 